\title{
Ballistic Range Testing of the Mars Exploration Rover Entry Capsule
}

\author{
Mark Schoenenberger, ${ }^{*}$ ASA Langley Research Center, Hampton, VA \\ Wayne Hathaway, ${ }^{\dagger}$ Arrow Tech Associates, So. Burlington, VT \\ Leslie Yates, ${ }^{\ddagger}$ AerospaceComputing Inc., Mountain View, CA \\ Prasun Desai, ${ }^{\S}$ NASA Langley Research Center, Hampton, VA
}

\begin{abstract}
Results from a 25 shot ballistic range test of the Mars Exploration Rover (MER) aeroshell are presented. The supersonic pitch damping properties of the MER capsule were characterized between $M a c h=1.5$ and $M a c h=3.5$ and total angles-of-attack from $0^{\circ}$ to greater than $25^{\circ}$. Three capsule center-of-gravity positions were tested across this range of conditions, $0.27,0.30$ and 0.33 body diameters aft of the nose. Parameter identification results show that the capsule is dynamically unstable at low angles-of-attack across the Mach numbers tested, with instability increasing with lower speeds. This dynamic instability was seen to increase with aft center-of-gravity movement. The MER outer mold line was very similar to the successful Mars Pathfinder capsule with only minor modifications. Pathfinder relied on Viking forced oscillation data for preflight predictions. The pitch damping data calculated from this test program are shown to more accurately reproduce the measured Pathfinder flight data.
\end{abstract}

\section{Nomenclature}

$\begin{array}{llll}C_{A} & \text { Axial force coefficient } & \gamma & \text { Linear damping constant } \\ C_{L} & \text { Lift coefficient } & \rho & \text { Density, } \mathrm{kg} / \mathrm{m}^{3} \\ C_{m} & \text { Pitching moment coefficient } & \sigma & \text { Radius of gyration, } \sqrt{I / m} \\ C_{m_{q}}+C_{m_{\dot{\alpha}}} & \text { Pitching damping coefficient } & \theta, \psi & \text { Fixed plane Euler angles, deg } \\ C_{N} & \text { Normal Force coefficient } & \omega & \text { Linear frequency constant } \\ D & \text { Reference diameter, } m & \text { Subscripts } & \\ I & \text { Moment-of-inertia, } g-m m^{2} & i & \text { Initial } \\ m & \text { Mass, } k g & q & \text { Pitch rate }(\mathrm{rad} / \mathrm{s}) \\ M & \text { Mach number } & T & \text { Total } \\ S & \text { Reference area, } m^{2} & c g & \text { Center-of-gravity } \\ V & \text { Velocity, } m / s & x x, y y, z z & \text { Moment of inertia axes } \\ x, y, z & \text { Cartesian position dimensions } & \alpha & \text { Derivative wrt angle-of-attack } \\ \alpha & \text { Angle-of-attack, deg } & \infty & \text { Freestream conditions }\end{array}$

\footnotetext{
*Aerospace Engineer, Exploration Systems Engineering Branch, Member AIAA

$\dagger$ Vice President of Engineering, Senior Member, AIAA

$\ddagger$ Vice President, Senior Member AIAA

$\S$ Aerospace Engineer, Exploration Systems Engineering Branch, Associate Fellow AIAA
} 


\section{Introduction}

The Mars Exploration Rovers (MER), "Spirit" and "Opportunity" successfully landed on Mars on January 3rd and 24th, 2004. A safe flight through the Martian atmosphere was critical to that success. One key constraint on the entry trajectory was that the aeroshell be sufficiently dynamically stable to limit the total angle-ofattack to less than $15^{\circ}$ at parachute deployment. This constraint was to ensure a safe capsule attitude for the deployment events. As the MER capsule had no active control and only minimal gyroscopic stability (constant roll rate of $12 \mathrm{deg} / \mathrm{s}$ ), accurate knowledge of the static and dynamic aerodynamics of the vehicle was important. Entry predictions for the Mars Pathfinder (MPF) capsule, which had a nearly identical outer mold line (OML) to MER, relied on computational data for the static stability and Viking forced oscillation data $^{1}$ for dynamic stability below Mach $=3.0$. While MPF (and MER) had a $70^{\circ}$ sphere-cone forebody taken from the Viking capsule, the backshells were notably different and the Viking center-of-gravity (cg) was farther forward. No ballistic range testing was performed for MPF due to project budget constraints, so the best available data (Viking) were used. The attitude of the MPF capsule at parachute deploy was higher than preflight predictions indicated. Comparison of the reconstructed flight data with preflight predictions suggested that the Viking data underpredicted the supersonic dynamic instability of the MPF capsule. As MER was following a shallower entry than Pathfinder, it was feared that the longer entry time would allow even greater growth in oscillation amplitude prior to parachute deployment. This concern prompted the MER project to obtain experimental data of the dynamic stability of the MER entry capsule.

Ballistic range testing was selected to quantify the

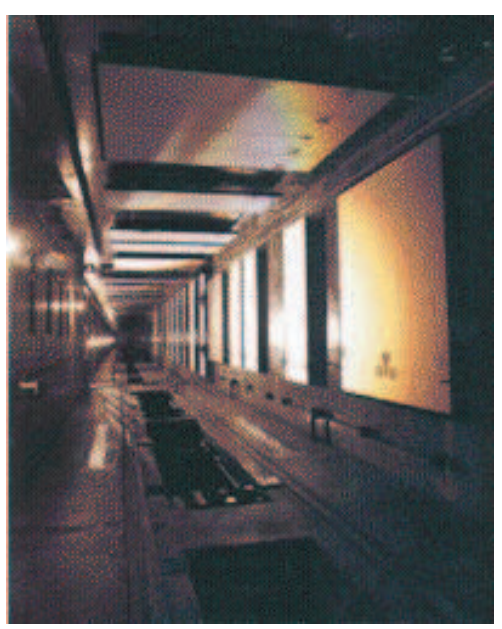
dynamic stability of the MER capsule. In recent years, the fidelity of parameters extracted from ballistic range data has improved significantly for blunt bodies. ${ }^{2,3}$ This technique is still limited by the uncertainties inherent in identifying aerodynamic properties using relatively few data points of a capsule that is rapidly changing speed and oscillation amplitude. However, the absence of sting effects offers an advantage over forced oscillation techniques for blunt bodies where base flows significantly influence the aerodynamic characteristics. Teramoto et $\mathrm{al}^{4}$ have shown intriguing computational results demonstrating the role of the wake structure in driving supersonic dynamic stability. Forced oscillation data, while more accurately measured, may be adversely disrupted by sting effects. ${ }^{5}$ This is especially true for blunt entry capsules where wake effects drive the dynamic instabilities.

Figure 1. ARF Test Range Hallway

\section{Facility and Methods}

\section{A. Aeroballistic Research Facility (ARF)}

Two series of ballistic range tests were conducted in February/March and September of 2001 at the Aeroballistic Research Facility (ARF) at Eglin Air Force Base. At the time of testing the ARF facility was operated jointly by the Air Force and the University of Florida. The facility consists of a gun room, blast chamber and instrumented range. The powder charge gun that propels the models, housed in the gun room, fires into the blast chamber. The blast chamber is simply another enclosed room designed to contain the explosive products of firing the gun and prevent unwanted light and debris from reaching the instrumented range. The model enters the test range through a small opening at the far end of the blast chamber. The instrumented range (Figure 1) is $207 \mathrm{~m}$ long with a $3.66 \mathrm{x} 3.66 \mathrm{~m}$ square cross section for the first $69 \mathrm{~m}$ and opens up to $4.88 \mathrm{x}$ $4.88 \mathrm{~m}$ for the remainder. Fifty orthogonal spark shadowgraph stations ("Hall" cameras pointed horizontally across the hall and "Pit" cameras pointed vertically from a trench in the floor) are located along the length of 
the range. The spacing of the stations is somewhat irregular to ensure the oscillation frequencies determined from the images are unique. The fields-of-view of these shadowgraph stations are $2.13 \mathrm{~m}$ diameter circles. All testing is in air and at atmospheric conditions.

The orthogonal shadowgraphs record the position and orientation of the model at precise times during its flight. A chronograph is synchronized with the spark source discharge (light source for the shadowgraphs) to mark the time each image is captured. The instantaneous orientation and position of the model is determined at each station from these images. The aerodynamic properties of the model are then extracted by parameter identification techniques.

Initial velocity was controlled to some extent by varying the amount of charge used in the launch gun. The amount required is determined from historical tables, kept for the gun at the ARF, based on the model mass. Initial angle-of-attack was controlled to some extent by placing photographic paper partially in the path of the model as it entered the test range. As part of the forebody strikes the photographic paper, it is given a small disturbance which starts the model oscillating. By using more pieces of paper stacked together, the initial oscillation amplitude can be increased. A maximum of 3 pieces of paper were used which could produce oscillations of about $25^{\circ}$. The operation of the ARF has been well documented in earlier work. ${ }^{6}$

\section{B. Model Geometry}

Figure 2 shows the OML dimensions of the test models and the components which were assembled to create the three cg locations. Each has an overall diameter of $70 \mathrm{~mm}$ and length of $39.62 \mathrm{~mm}$, which is $2.64 \%$ of the MER flight vehicle dimensions. Combining materials of different densities in different proportions allowed control of the axial position of the cg. Tungsten was used to ballast the models and steel or aluminum was used to make the body of the models. Different size tungsten inserts were press-fit into the bodies for each cg position. Table 1 lists the dimensions of the components for each combination of plug size and forebody material used to make up the three cg locations. Models 100, 200 and 300 were used during an initial series of shots. Models 100a and 300a, along with more of model 200 were used for a supplemental series of shots. The new models were designed to increase the moments of inertia about the transverse axes as much as practical. This change was made in an attempt to reduce the oscillation frequency of the models as they proceeded down the range to provide more data points per cycle, improving data reduction accuracy. Table 2 shows the design mass properties of the models. The mass properties of models were measured prior to testing and each was found to be very close to these design numbers (within $0.1 \%$ ).

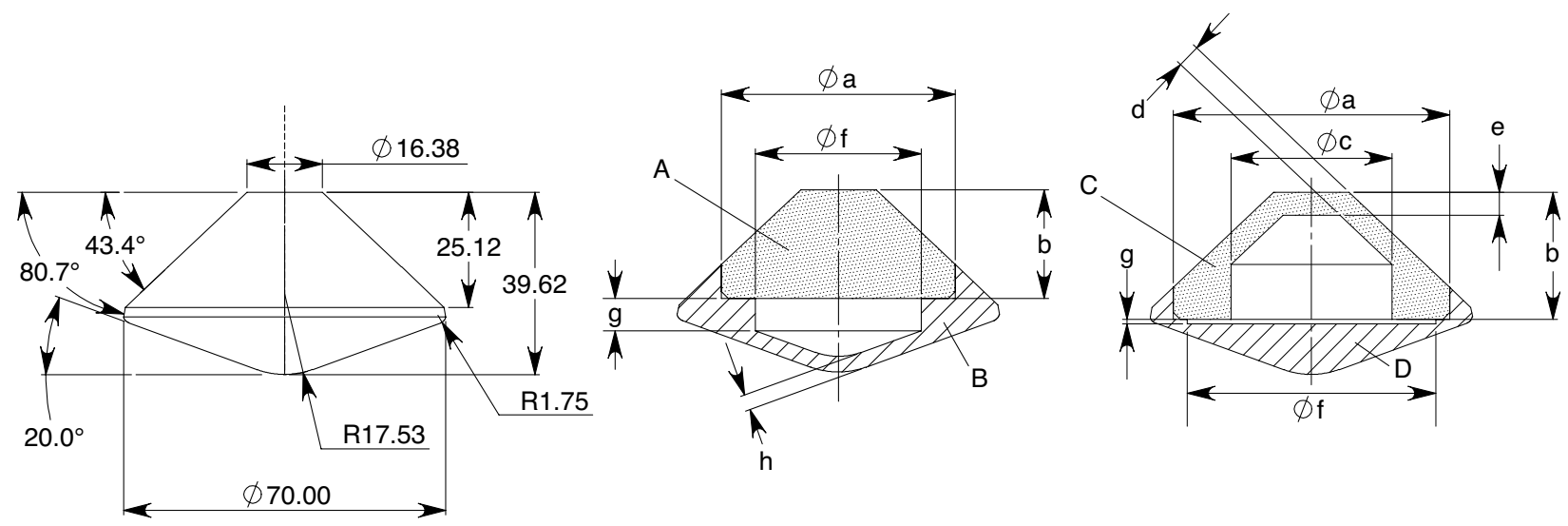

Figure 2. Model dimensions (millimeters). See Table 1 for parametric dimensions

\section{Test Matrix}

The test matrix was designed to obtain data with the models flying across a range of oscillation amplitudes and speeds from Mach 4 down to Mach 1.5. MPF flight data suggested that MER would become dynamically 
Table 1. Parametric Model Dimensions (in millimeters) and Materials (see Figure 2)

\begin{tabular}{cccccccccccc} 
Model & $x_{c g} / D$ & Config. & $\mathrm{a}$ & $\mathrm{b}$ & $\mathrm{c}$ & $\mathrm{d}$ & $\mathrm{e}$ & $\mathrm{f}$ & $\mathrm{g}$ & $\mathrm{h}$ & $\begin{array}{c}\text { Material } \\
\text { Back/Front }\end{array}$ \\
\hline \hline 100 & 0.27 & A-D & 25.37 & 11.62 & $\mathrm{n} / \mathrm{a}$ & $\mathrm{n} / \mathrm{a}$ & $\mathrm{n} / \mathrm{a}$ & 19.37 & 2.00 & $\mathrm{n} / \mathrm{a}$ & $\mathrm{W} /$ Steel \\
$100 a$ & 0.27 & C-D & 60.00 & 27.62 & 35.00 & 5.00 & 5.00 & 54.03 & 1.00 & 3.00 & $\mathrm{~W} /$ Steel \\
200 & 0.30 & A-B & 50.80 & 23.62 & $\mathrm{n} / \mathrm{a}$ & $\mathrm{n} / \mathrm{a}$ & $\mathrm{n} / \mathrm{a}$ & 36.00 & $\mathrm{n} / \mathrm{a}$ & $\mathrm{n} / \mathrm{a}$ & $\mathrm{W} /$ Steel \\
300 & 0.33 & A-B & 50.80 & 23.62 & $\mathrm{n} / \mathrm{a}$ & $\mathrm{n} / \mathrm{a}$ & $\mathrm{n} / \mathrm{a}$ & 43.00 & $\mathrm{n} / \mathrm{a}$ & 3.00 & $\mathrm{~W} / \mathrm{Al}$ \\
$300 a$ & 0.33 & C-B & 60.00 & 25.62 & 40.00 & 5.00 & 17.00 & 55.00 & $\mathrm{n} / \mathrm{a}$ & 3.00 & $\mathrm{~W} / \mathrm{Al}$ \\
\hline
\end{tabular}

${ }^{*} \mathrm{~W}$ : Tungsten, Al: Aluminum

Table 2. Model Mass Properties

\begin{tabular}{ccccc} 
Model & $x_{c g} / D$ & $\begin{array}{c}\text { Mass } \\
g\end{array}$ & $\begin{array}{c}I_{z z} \\
\left(g-m m^{2}\right) \cdot 10^{-5}\end{array}$ & $\begin{array}{c}I_{x x}, I_{y y} \\
\left(g-m m^{2}\right) \cdot 10^{-5}\end{array}$ \\
\hline \hline 100 & 0.27 & 584 & 2.21 & 1.55 \\
200 & 0.30 & 767 & 2.85 & 1.86 \\
300 & 0.33 & 617 & 1.89 & 1.22 \\
$100 a$ & 0.27 & 684 & 3.31 & 2.10 \\
$300 a$ & 0.33 & 572 & 2.32 & 1.45 \\
sabot & - & 248 & 1.96 & 1.98 \\
\hline
\end{tabular}

unstable between Mach 3.0 and 3.5. The upper bound of this Mach range was chosen to provide data prior to the onset of the dynamic instability. The lower bound was chosen to provide data at or below the expected parachute deployment conditions. Previous tests on other geometries suggested that the pitch damping for blunt bodies is very nonlinear with angle-of-attack. Therefore, data were needed for a wide range of oscillation amplitudes. The target Mach and angle-of-attack ranges were broken into smaller regions which helped guide the shot selection. Data were sought at low (0-5), medium (5-15) and large (15+) total anglesof-attack to better define the pitch damping nonlinearity. It was attempted to capture oscillations at each of these amplitude ranges for low (less than $\mathrm{M}=1.6)$, medium $(\mathrm{M}=1.6-2.5)$ and high $(\mathrm{M}=2.5+)$ speeds. As low-speed/low-angle data were not not fully captured in the first test series, the second series of slower, unperturbed shots were conducted several months after the first series. Table 3 shows the test conditions for each of the 25 shots. Shots 23-39 represent the February/March 2001 shots, while shots 57-65 were conducted in September, 2001.

\section{Data Reduction}

The shadowgraph negatives were scanned into digital format and the orientation and position of the model was determined from the two orthogonal views at each station. A set of catenary wires is arranged in the tunnel to form the reference points in each shadowgraph. Small beads on the wires mark known points in the images which allow accurate measurement of the model position. For these blunt models, determining the model orientation is more difficult than for slender bodies with long spin axes. The Comprehensive Automated Data Reduction and Analysis System (CADRA) by Yates ${ }^{7}$ was used for the film reading and trajectory calculations, and determining the fixed plane Euler angles based on the backshell cone angle. Measuring the forebody angle is much more difficult due to the more severe distortion of the shadowgraph image due to the bow shock in front of the model. Measurements of the orientation angles $(\theta, \psi)$ of the model are measured accurate to $\pm 0.5^{\circ}$ for the MER model. 
Table 3. Test Conditions

\begin{tabular}{cccccccccc}
\hline \hline $\begin{array}{c}\text { Model } \\
\text { No. }\end{array}$ & $\begin{array}{c}\text { Shot } \\
\text { No. }\end{array}$ & $\begin{array}{c}\text { No. of } \\
\text { Stations/ } \\
\text { Dist. }[\mathrm{m}]\end{array}$ & $\begin{array}{c}\text { Pressure } \\
{[\mathrm{mbar}]}\end{array}$ & $\begin{array}{c}\text { Temperature } \\
{\left[\mathrm{C}^{\circ}\right]}\end{array}$ & $\begin{array}{c}\text { Relative } \\
\text { Humidity } \\
{[\%]}\end{array}$ & $\begin{array}{c}\text { Density } \\
{\left[\mathrm{kg} / \mathrm{m}^{3}\right]}\end{array}$ & $\begin{array}{c}\text { Speed of } \\
\text { Sound } \\
{[\mathrm{m} / \mathrm{s}]}\end{array}$ & $\begin{array}{c}\text { Initial } \\
\text { Mach }\end{array}$ & $\begin{array}{c}\text { Final } \\
\text { Mach }\end{array}$ \\
\hline \hline 307 & 23 & $50 / 201$ & 1027.4 & 22.0 & 84 & 1.2124 & 344.43 & 3.70 & 1.26 \\
300 & 24 & $50 / 201$ & 1026.1 & 25.4 & 64 & 1.1971 & 346.41 & 3.70 & 1.28 \\
301 & 25 & $50 / 201$ & 1023.7 & 22.4 & 61 & 1.2064 & 344.66 & 3.90 & 1.51 \\
202 & 26 & $50 / 201$ & 1023.0 & 21.7 & 59 & 1.2085 & 344.26 & 3.90 & 1.65 \\
101 & 28 & $50 / 201$ & 1016.6 & 22.0 & 58 & 1.1997 & 344.43 & 3.70 & 1.23 \\
203 & 29 & $50 / 201$ & 999.0 & 22.9 & 62 & 1.1754 & 344.96 & 3.90 & 1.68 \\
105 & 30 & $50 / 201$ & 1009.8 & 23.0 & 65 & 1.1877 & 345.01 & 3.86 & 1.64 \\
103 & 31 & $50 / 201$ & 1009.5 & 22.8 & 68 & 1.1881 & 344.90 & 3.96 & 1.28 \\
303 & 32 & $50 / 201$ & 1021.7 & 21.0 & 58 & 1.2098 & 343.85 & 3.70 & 1.46 \\
204 & 33 & $50 / 201$ & 1024.1 & 20.1 & 46 & 1.2164 & 343.32 & 3.65 & 1.63 \\
104 & 34 & $50 / 201$ & 1023.4 & 20.4 & 46 & 1.2143 & 343.50 & 3.03 & 1.01 \\
302 & 35 & $50 / 201$ & 1020.0 & 20.9 & 45 & 1.2082 & 343.79 & 3.10 & 1.15 \\
205 & 36 & $50 / 201$ & 1023.4 & 22.6 & 42 & 1.2053 & 344.78 & 3.05 & 1.31 \\
206 & 37 & $50 / 201$ & 1023.7 & 21.5 & 42 & 1.2101 & 344.14 & 3.05 & 1.35 \\
102 & 38 & $50 / 201$ & 1022.0 & 21.9 & 41 & 1.2065 & 344.37 & 3.10 & 1.33 \\
304 & 39 & $50 / 201$ & 1023.0 & 21.9 & 42 & 1.2077 & 344.37 & 2.90 & 1.20 \\
$307 \mathrm{a}$ & 57 & $31 / 110$ & 1017.95 & 21.95 & 57 & 1.2015 & 344.40 & 2.00 & 1.00 \\
$108 \mathrm{a}$ & 58 & $35 / 131$ & 1017.95 & 22.55 & 57 & 1.1991 & 344.75 & 2.00 & 1.00 \\
209 & 59 & $33 / 120$ & 1011.51 & 22.75 & 60 & 1.1907 & 344.87 & 2.00 & 1.00 \\
$305 \mathrm{a}$ & 60 & $39 / 147$ & 1017.61 & 22.75 & 56 & 1.1979 & 344.87 & 2.30 & 1.00 \\
$106 \mathrm{a}$ & 61 & $46 / 183$ & 1018.63 & 22.15 & 55 & 1.2015 & 344.52 & 2.20 & 1.00 \\
207 & 62 & $50 / 201$ & 1018.63 & 22.65 & 56 & 1.1995 & 344.81 & 2.25 & 1.00 \\
$306 \mathrm{a}$ & 63 & $43 / 165$ & 1015.92 & 21.45 & 56 & 1.2011 & 344.11 & 2.56 & 1.00 \\
$107 \mathrm{a}$ & 64 & $49 / 197$ & 1017.61 & 22.65 & 56 & 1.1983 & 344.81 & 2.56 & 1.00 \\
208 & 65 & $48 / 48$ & 1017.61 & 20.65 & 55 & 1.2064 & 343.64 & 2.56 & 1.00 \\
& & & & & & & & & \\
\hline \hline & & & & & & & & &
\end{tabular}

Figure 3 shows a sample of 4 sets of orthogonal shadowgraphs, taken from Shot 64, used to determine the orientation and position of the model. The distortion of the forebody shadow is evident in these images. From these pictures, the two fixed plane Euler angles, $\theta$ and $\psi$ are determined along with their $\mathrm{x}$ (downrange), $\mathrm{y}$ (horizontal) and $\mathrm{z}$ (vertical) positions at the time the images were taken.

Extraction of the aerodynamic coefficients and derivatives is the primary goal in analyzing the trajectories measured in the ARF. The ARF Data Analysis System (ARFDAS) was used to extract this data. An overview of this data analysis is described by Fischer and Hathaway. ${ }^{8}$ ARFDAS incorporates a standard linear theory analysis ${ }^{9,10}$ and a 6-Degree-of-Freedom (6-DoF) numerical integration technique . The 6-DoF routine incorporates the Maximum Likelihood Method (MLM) to match the theoretical trajectory to the experimentally measured trajectory. The MLM is an iterative procedure that adjusts the aerodynamic coefficients to maximize a likelihood function. ${ }^{11}$ The use of this likelihood function eliminates the inherent assumption in least squares theory that the magnitude of the measurement noise must be consistent between 

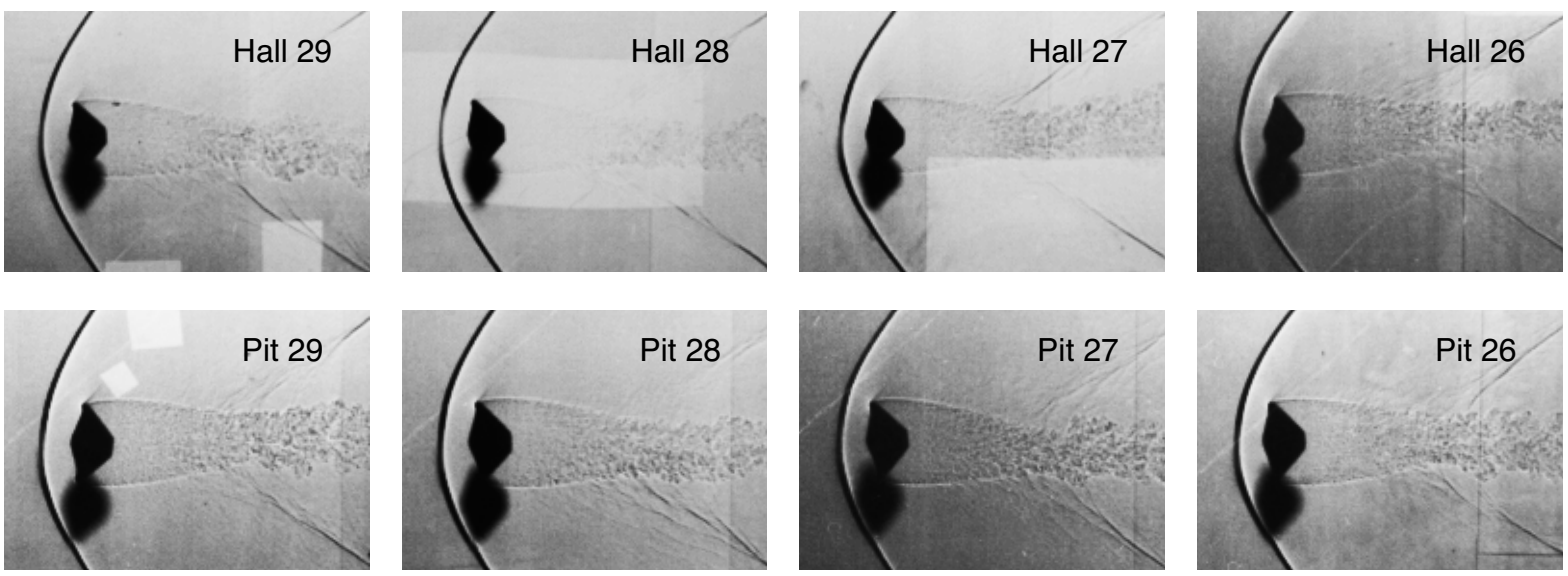

Figure 3. Subset of images (cropped) collected from Shot 64. Subsequent downrange images from right to left.

dynamic parameters (irrespective of units). In general, the aerodynamics can be nonlinear functions of the angle-of-attack, Mach number, and aerodynamic roll angle. ARFDAS is capable of analyzing both symmetric and asymmetric bodies. The essential steps of the data reduction system are to: (a) assemble the dynamic range data (time, position, attitude), physical properties, and atmospheric conditions, (b) perform linear theory analysis, and (c) perform 6-DoF analysis for final aerodynamics. Each model fired in the ARF was initially analyzed separately, then combined in appropriate groups, including segments from different shots, for simultaneous analysis using a multiple fit capability. This provides a common set of aerodynamics that match each of the separately measured position-attitude-time profiles. The multiple fit approach provides a more complete spectrum of angular and translational motion than would be available from any one trajectory considered separately. This increases the probability that the determined coefficients define the model's aerodynamics over the entire range of test conditions.

Figure 4 shows a typical ARFDAS least squares fit to angle and position data obtained from images scanned from ballistic range shot 64. The agreement between ARFDAs 6-DoF simulation using the identified aerodynamics and the ballistic range data is excellent. To better understand the oscillations shown in Figures $4 \mathrm{a}$ and $\mathrm{b}$, consider Equation 1:

$$
\ddot{\alpha}-\frac{\rho V S}{2 m}\left(-C_{L_{\alpha}}+\left(C_{m_{q}}+C_{m_{\dot{\alpha}}}\right) \frac{D^{2}}{2 \sigma^{2}}\right) \dot{\alpha}-\frac{\rho V^{2} D}{2 I} C_{m_{\alpha}} \alpha=0
$$

This expression is a planar linearization of the 6-DoF angular acceleration equations and assumes small angles and linear forces and moments. ${ }^{10,12}$ This equation shall be referred to later to qualitatively illustrate the dominant terms driving the observed phenomena. For constant coefficients, the solution for Equation 1 is of the form of a harmonic oscillator with damping:

$$
\alpha(t)=\alpha_{o} e^{\gamma t} \cos (\omega t)
$$

Where

$$
\gamma=\frac{\rho V S}{2 m}\left(-C_{L_{\alpha}}+\left(C_{m_{q}}+C_{m_{\dot{\alpha}}}\right) \frac{D^{2}}{2 \sigma^{2}}\right)
$$

and 


$$
\omega=\sqrt{-\frac{\rho V^{2} S D}{2 I} C_{m_{\alpha}}-\gamma^{2}}
$$

In Equation 2, $\gamma$ is a damping term, dominated by $C_{m_{q}}+C_{m_{\dot{\alpha}}}$. A positive value (positive $C_{m_{q}}+C_{m_{\dot{\alpha}}}$ ) causes a growth in amplitude, while a negative value damps out any oscillations. In Equation $2, \omega$ is a frequency term, dominated by the square root of the static stability, $C_{m_{\alpha}}$. So, to a first order of magnitude, the data in Figures $4 \mathrm{a}$ and $\mathrm{b}$ show a statically stable capsule with an integrated pitch damping that is positive or dynamically unstable. Chapman and Yates provide much more detail regarding these equations, but Equations 1-4 shall be used to help interpret the motion plots in Section III.

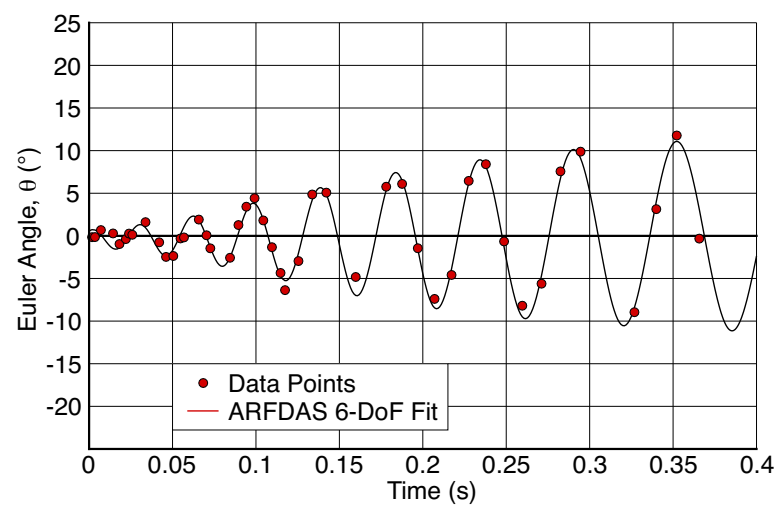

(a) Euler Angle, theta

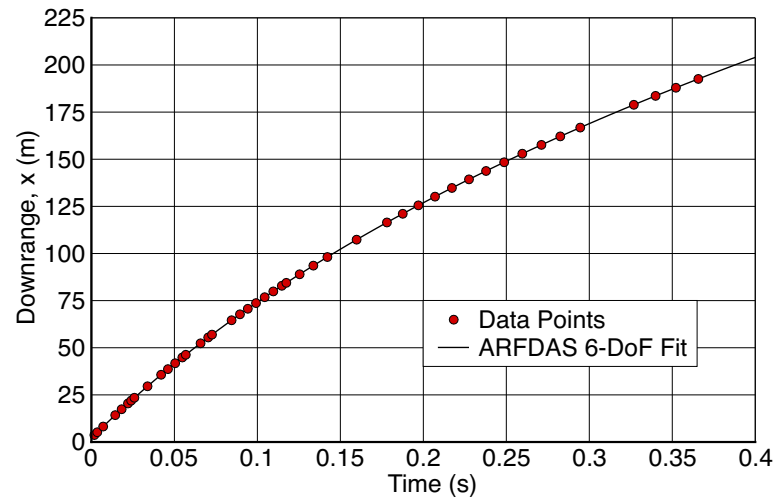

(c) Downrange

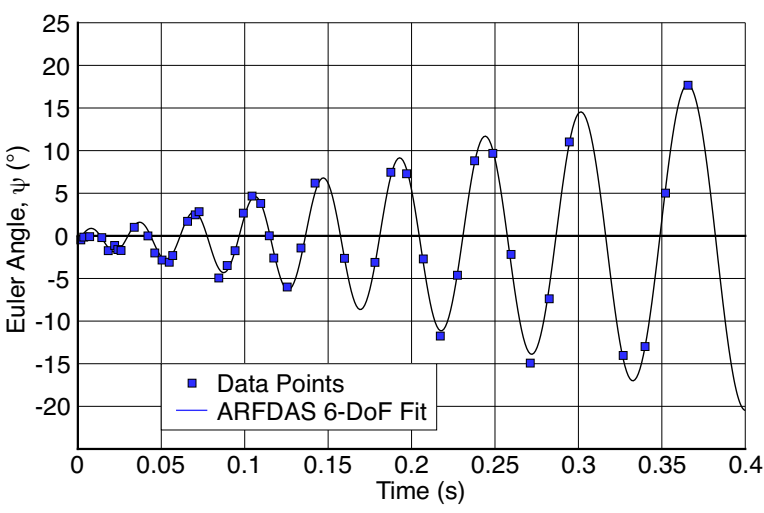

(b) Euler Angle, psi

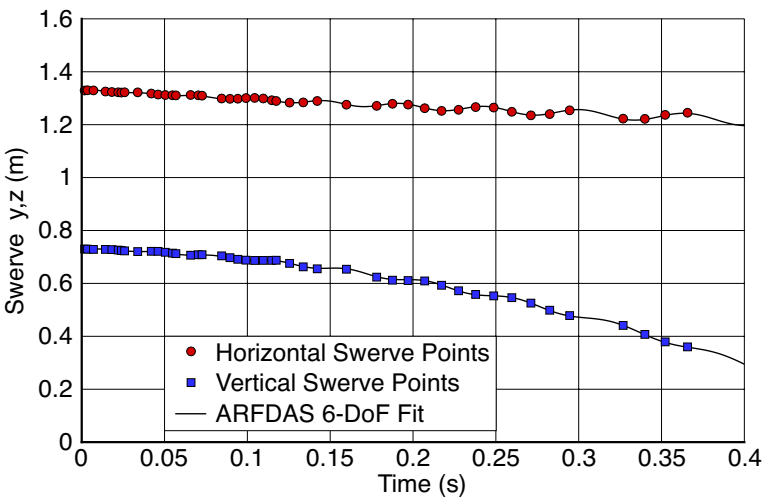

(d) Vertical, Horizontal Swerve

Figure 4. Comparison of ARFDAS data reduction with Shot 64 data points, scanned from shadowgraphs.

Another independent data reduction effort was performed concurrently with the analysis presented to add confidence in the final results. ${ }^{13}$ Simulations using each set of pitch damping results showed very similar predictions of the capsule dynamics. The nonlinear character of the pitch damping with angle-of-attack and variation with Mach number as determined by both parameter identification efforts were in very good agreement.

\section{Results}

A matrix of Mach/angle-of-attack bins is shown in Figure 5 to illustrate how the desired test space was populated. Each model in the figure represents a segment of useful data obtained in the corresponding speed 
and attitude range. Each model does not represent a complete shot. This data set represents the most extensive set of ballistic range data for a $70^{\circ}$ sphere-cone, used for dynamic stability parameter identification.

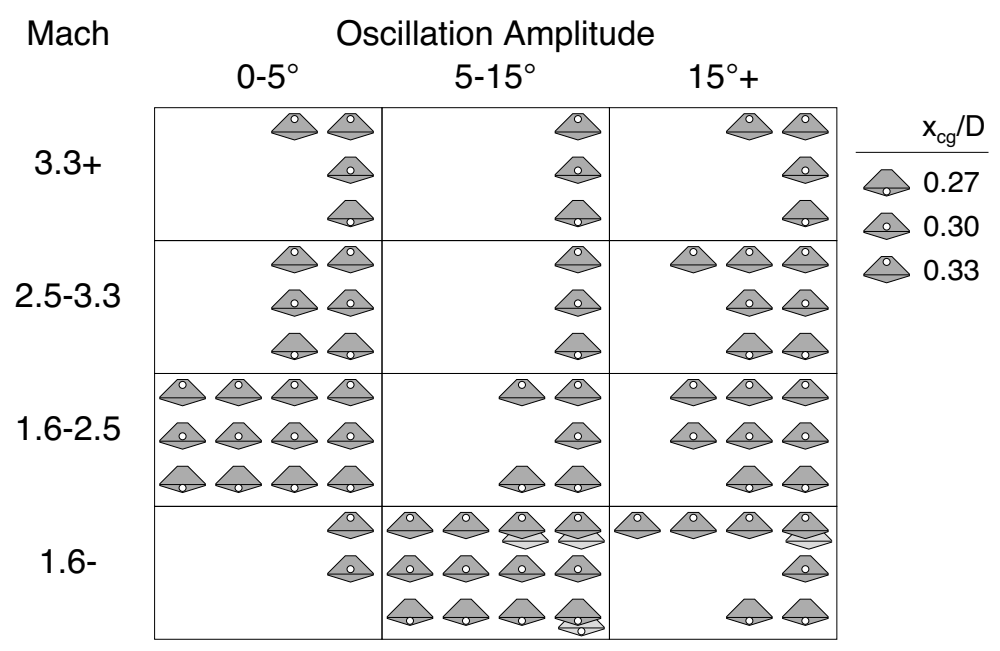

Figure 5. Population of desired Mach- $\alpha$ conditions.

\section{A. Static Aerodynamics}

The static aerodynamics, while not a primary objective of the test, are important in extracting dynamic aerodynamics. For a look at the significant terms contributing to the pitch damping of the capsule, the lift coefficient can be re-expressed in terms of coefficients in the body axes:

$$
C_{L}=-C_{A} \sin \alpha_{T}+C_{N} \cos \alpha_{T}
$$

For blunt bodies, $C_{N}$ is much smaller than $C_{A}$ at small angles. The lift curve slope is dominated by the axial force coefficient for the range of angles tested here:

$$
C_{L_{\alpha}}=-C_{A} \cos \alpha_{T}-C_{N} \sin \alpha_{T} \approx-C_{A}
$$

Recalling Equation 1, the axial force and static stability coefficients are the critical parameters to capture properly to extract the pitch damping coefficient. Again, this is a qualitative description of the dominant terms. The ARFDAS analysis fits equations through the full 6 -DoF equations of motion.

Figure 6 shows the axial force coefficient results from linear sectional fits, and the multi-fit results from 6-DoF trajectory simulations $\left(C_{A}=\right.$ Force $\left._{\text {Axial }} / \frac{1}{2} \rho_{\infty} V_{\infty}^{2} S\right)$. As the oscillations of all shots grew in amplitude as they decelerated, there are few points at low angles-of-attach and low Mach number. The multi-fit curves in Figure $6 \mathrm{~b}$ are therefore extrapolations from higher angle data. Looking at the Mach $=1.5$ curve as an example, there are no data for speeds less than Mach $=1.5$ below $\alpha_{T}=6^{\circ}$. No data points at any speed indicate a $C_{A}$ near 1.6. Therefore, the low-angle, low-Mach segments of the 6 -DoF fits have greater uncertainty than the regions fit through data points. The functional form of the $C_{A}$ curves were not permitted to vary in the data reduction and the sectional results hint that $C_{A}$ varies with $\alpha_{T}$ differently at different Mach numbers (less variation with $\alpha_{T}$ at high speeds, more at lower speeds). Improving the functional form of the axial force coefficient, was not a priority as these results are valid over the Mach and attitude ranges required to resolve the dynamic data. Considering the known limitations of the ballistic range data reduction methods, these results are in excellent agreement with the MER static aerodynamics database, ${ }^{13}$ and Viking data. $^{14}$ 


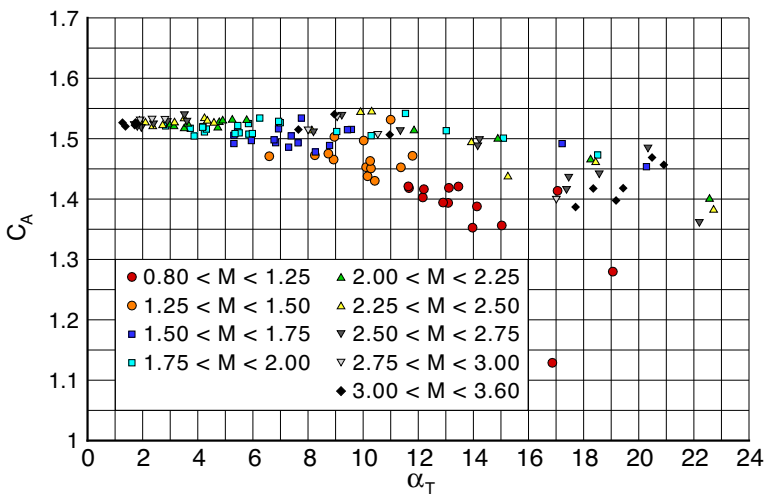

(a) Linear sectional fits

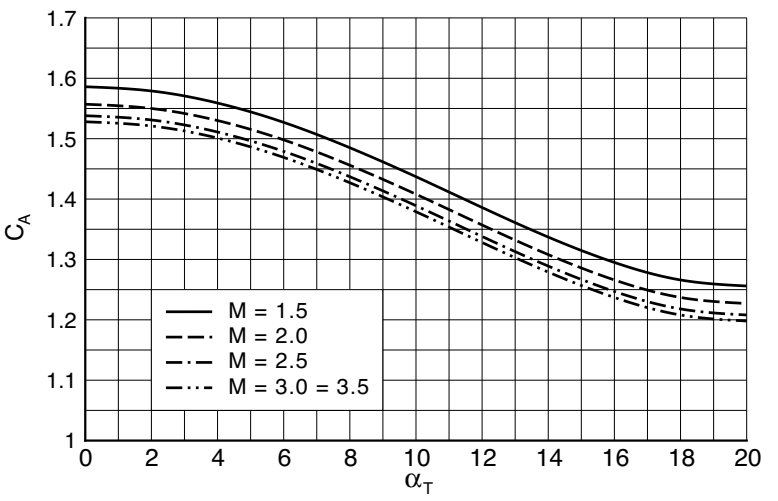

(b) Multi-fit

Figure 6. Axial force coefficient results

The pitching moment results are plotted in Figure $7\left(C_{m}=\right.$ Moment $\left._{p i t c h} / \frac{1}{2} \rho_{\infty} V_{\infty}^{2} S D, C_{m_{\alpha}}=\frac{\partial}{\partial \alpha} C_{m}\left(\mathrm{rad}^{-1}\right)\right)$. A cg sensitivity is seen in the linear sectional fits indicating decreased static stability with aft cg movement.

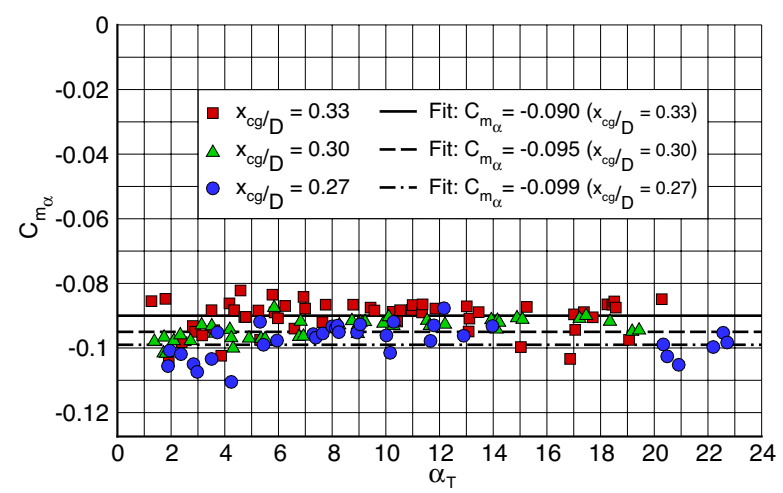

Figure 7. Pitching moment derivative results

Although there appears to be a slight sensitivity to angle-of-attack at low angles, overall the data are invariant with angle-of-attack and a constant $C_{m_{\alpha}}$ value was determined with the 6 -DoF multifit capability for each cg position (noted in Figure 7). Across the speed range tested, the pitching moment slopes were invariant with Mach number as well. The $C_{m_{\alpha}}$ values are in close agreement with the MER aerodynamic database and other data for $70^{\circ}$ sphere-cones. The normal force derivative with angle-of-attack $\left(C_{N_{\alpha}}\right)$ was also determined to be constant and invariant with cg position and Mach number. For blunt bodies like MER, $C_{N}$ is quite small compared to the axial force coefficient and therefore not a significant influence on the data reduction. Fitting the normal force through several multiple fits yielded a constant $C_{N_{\alpha}}$ of 0.20 . This value was used for all dynamic aerodynamic data reduction.

\section{B. Pitch Damping}

Figures 8a-f show the pitch damping results from all of the shots $\left(C_{m_{q}}+C_{m_{\dot{\alpha}}}=\left(\partial / \partial \frac{q D}{2 V}+\partial / \partial \frac{\dot{\alpha} D}{2 V}\right) C_{m}\right)$. Figures $8 \mathrm{a}, \mathrm{c}$ and e show the linear sectional fits for subsets of data grouped by cg location. The sectional fits map the general characteristics of the capsule's dynamic stability and help set the form functions used in the 6-DoF analysis.. The dynamic instability of the capsule at low angles-of-attack is clearly seen (positive $C_{m_{q}}+C_{m_{\dot{\alpha}}}$ ). The sectional fits for each center-of-gravity model also show a clear Mach sensitivity. High Mach shots are more dynamically stable and the capsule becomes less dynamically stable as it decelerates. Comparing Figures 8a, c and e, center-of-gravity variation is more difficult to detect by inspection in the linear fit scatter.

Figures $8 \mathrm{~b}, \mathrm{~d}$ and $\mathrm{f}$ show the results of the multi-fit 6-DoF analysis for each of the three cg positions tested. The default aerodynamic models in ARFDAS do not have the malleability to capture the nonlinearity shown 


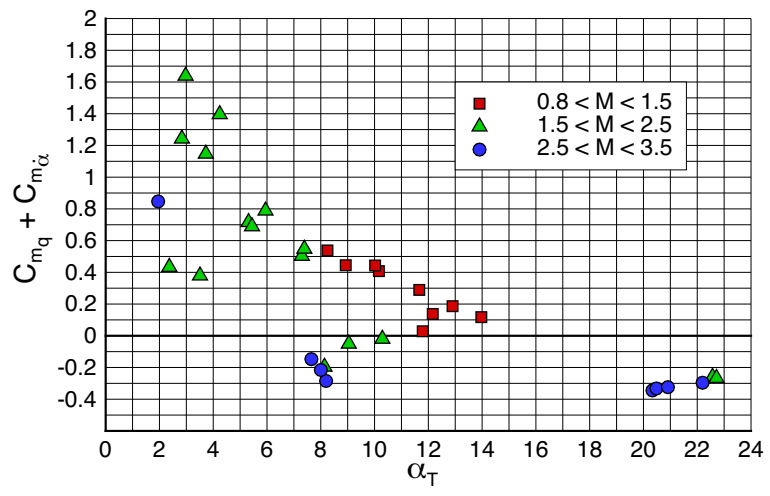

(a) Linear Fits, $0.27 \mathrm{cg}$

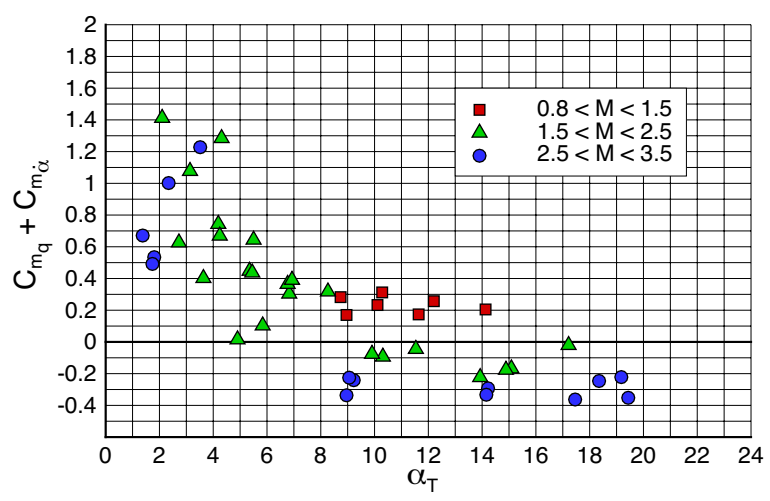

(c) Linear Fits, $0.30 \mathrm{cg}$

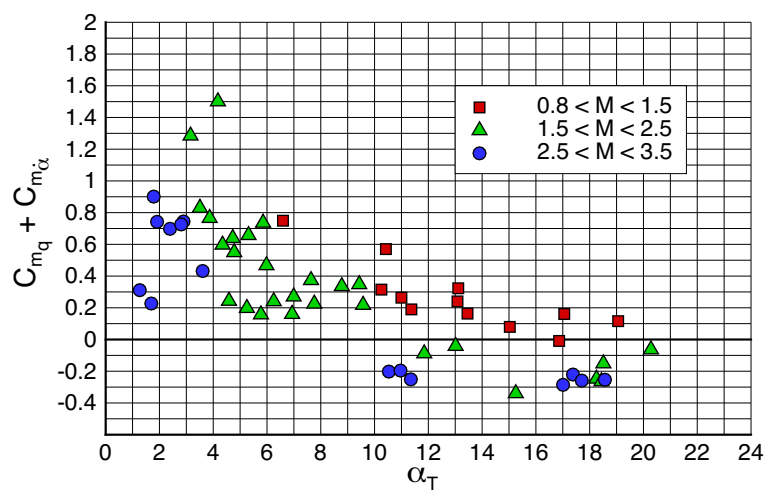

(e) Linear Fits, $0.33 \mathrm{cg}$

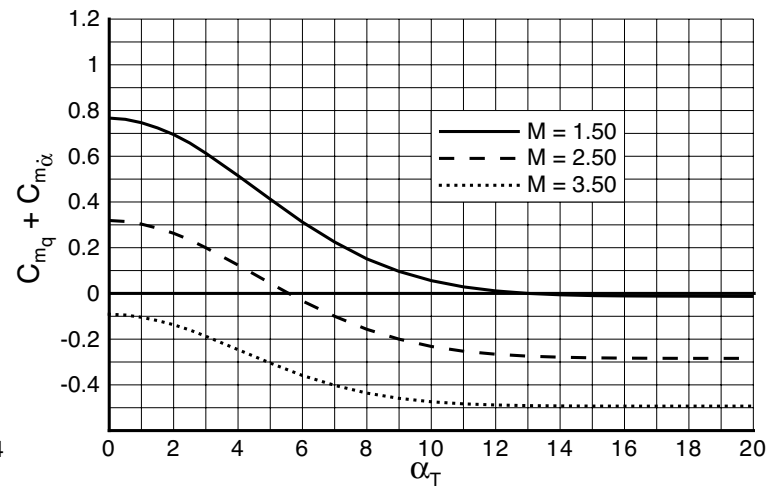

(b) 6-DoF Curves, $0.27 \mathrm{cg}$

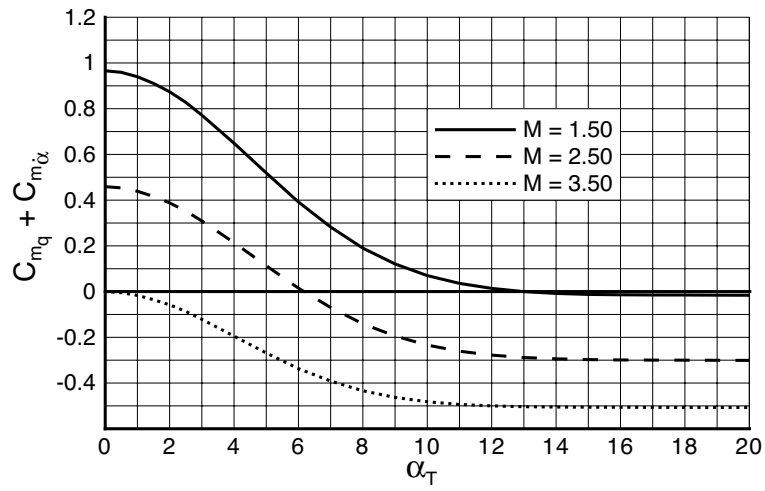

(d) 6-DoF Curves, $0.30 \mathrm{cg}$

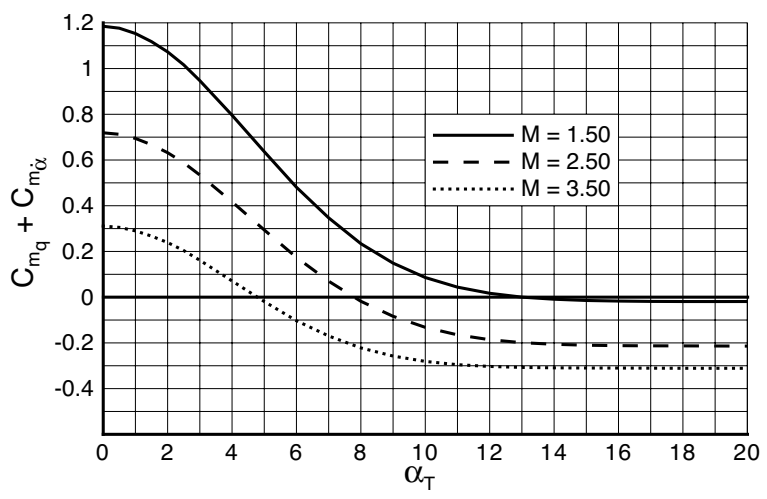

(f) 6-DoF Curves, $0.33 \mathrm{cg}$

Figure 8. Pitch damping, $C_{m_{q}}+C_{m_{\dot{\alpha}}}$, results. Note, linear sectional fits are approximate guides for 6-DoF form fit analysis. 
in these figures. Therefore, a sliding form fit option in ARFDAS was used to extract the pitch damping over smaller angle-of-attack ranges. These form fits were then pieced together to obtain the curves shown. These curves represent the final results of the parameter identification and show distinct trends in the dynamic stability with Mach number and cg location. At the higher speeds, the capsule becomes dynamically stable at higher angles-of-attack. Such pitch damping characteristics indicates limit cycle behavior ${ }^{12}$ for each $\mathrm{cg}$ position at the higher Mach numbers. At Mach $=1.5$, the parameter identification results indicate that the vehicle is dynamically unstable (or neutrally stable) even at high angles-of-attack.

The uncertainties placed on the pitch damping for the MER aerodynamic database were very conservative to account for testing uncertainties as well as uncertainties in using ground-based data to predict full-scale flight characteristics at Mars. The 3- $\sigma$ values are $+100 \%,-50 \%$ about the nominal data to account for uncertainties in extracting the nonlinear character of the curves. An adder of 0.0 to 0.10 was also added in the destabilizing direction to account for uncertainties in determining the Mach sensitivity.

\section{Motion Characteristics}

The ARFDAS parameter identification fits 6-DoF trajectories through data points extracted from the ballistic range shadowgraphs. The final aerodynamic results, static and dynamic aerodynamics, produce excellent reconstructions of the experimental data. An example of this is shown in Figure 4. Also, the motion of these trajectories best illustrates the flight characteristics of the capsule in each shot and helps to demonstrate the trends extracted from the full test matrix. The Mach and center-of-gravity sensitivities of the capsule are shown in Figures 9a and b.

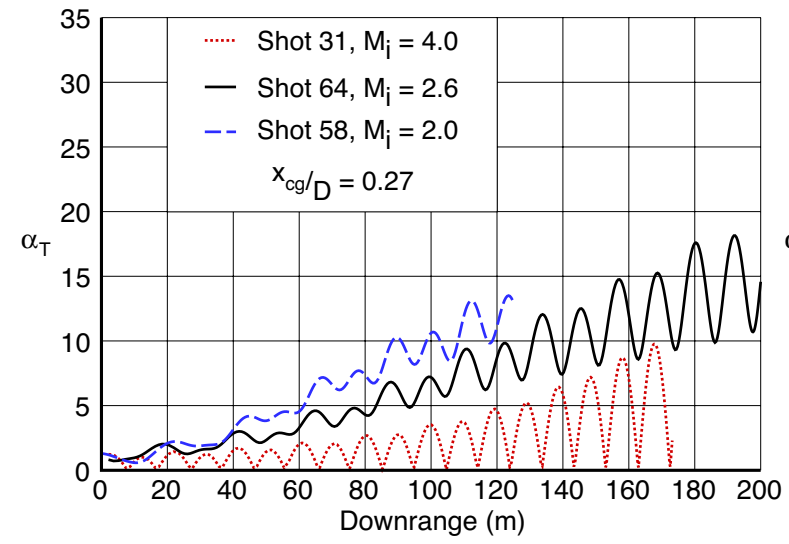

(a) Mach sensitivity

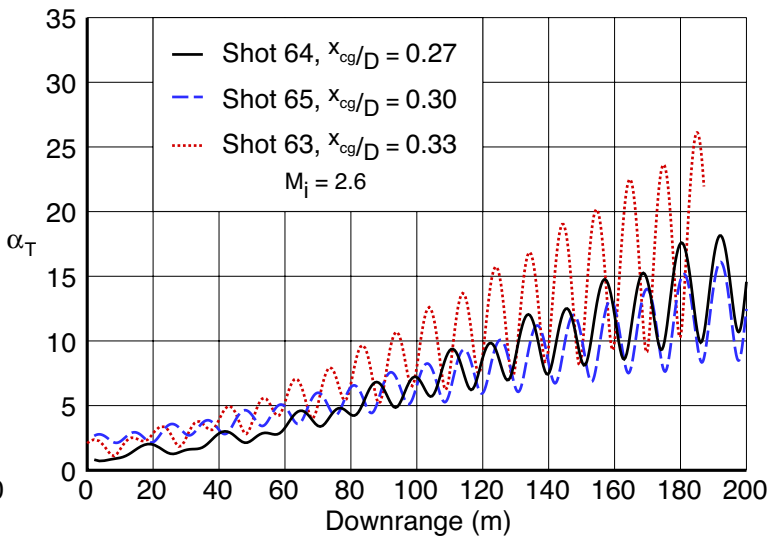

(b) Center-of-gravity sensitivity

Figure 9. Angular motion plots for several shots showing total angle-of-attack versus downrange position.

First, the angular motion in each of these shots show an attitude growth consistent with dynamic instability, while the frequency of oscillation is consistent with static stability. The curves show the total angle-ofattack of the capsule for several shots. The Mach sensitivity plot (Figure 9a) shows 3 shots that each start at roughly the same attitude, but have different initial velocities. The dynamic instability of the capsule worsens with slower initial velocity as $\alpha_{T}$ increases much more rapidly for the slower shots and the ARFDAS data reduction has shown that. Interpreting the center-of-gravity plot is more subtle and Figure $9 \mathrm{~b}$ serves more to illustrate the complexity of extracting the sensitivity than to show a trend. Each of the shots in Figure $9 \mathrm{~b}$ starts at roughly the same velocity $(\mathrm{M}=2.6)$ and $\alpha_{T}$. The $x_{c g} / D=0.27$ and 0.30 shots $(64,65)$ fall almost on top of each other, with the 0.27 shot actually growing to a slightly higher total angle-of-attack. The 0.33 shot (63) clearly grows to the highest amplitude. This observation is not the full story however. Note that the transverse-axes moments-of-inertia (Table 2) of the 0.27 models are $35 \%$ greater than the 0.30 
models. Referring back to Equation 1, and the damping term (Equation 3), the greater moments-of-inertia act to retard the attitude growth and account for the greater growth of the 0.30 shot. Conversely, the 0.33 model has the lowest moment-of-inertia of the three along with the furthest aft cg location. The larger angles-of-attack seen in shot 63 would likely have been less dramatic had the mass properties been more comparable to the other models. These differences are all taken into account in the full 6-DoF equations of motion in the data reduction, however. By fitting the $C_{m_{q}}$ values through all 25 shots, the actual trends are revealed. These plots show a consistent story, but the accuracy in determining trends requires many ballistic range shots covering a range of speeds and amplitudes for each cg position.

Several shots were perturbed prior to entering the instrumented range. Photographic paper was placed in the path of the models which induced oscillations. Figure 10 shows two examples of such cases. Figure 10a shows a high speed $\left(M_{i}=3.9\right)$ shot of the $x_{c g} / D=0.33$ model which was initially perturbed up to an attitude greater than $30^{\circ}$. At such high angles, the capsule is dynamically stable and is seen to decrease in amplitude down the range. Figure $10 \mathrm{~b}$ shows a slightly slower case $\left(M_{i}=3.7\right)$ that was perturbed to a less severe initial attitude of approximately $15^{\circ}$. This shot shows limit cycle behavior at this attitude for the first half of the flight. As the capsule decelerates however, the dynamic instability becomes worse and the oscillation amplitude increases. The select cases presented here are the most comparable of the test series and highlight the key features extracted from the full set of data.

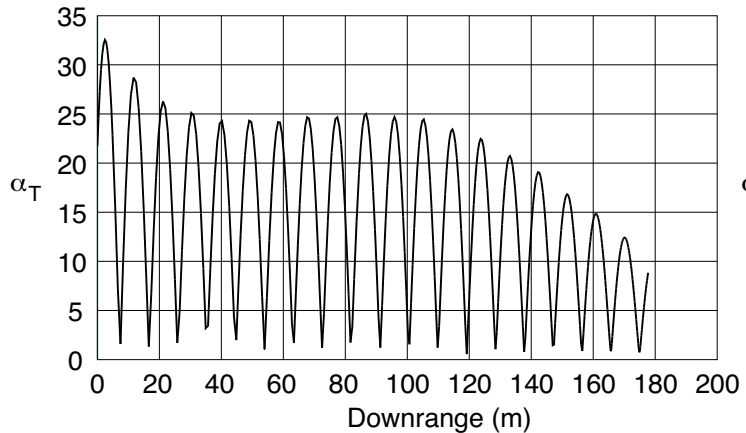

(a) Shot 25

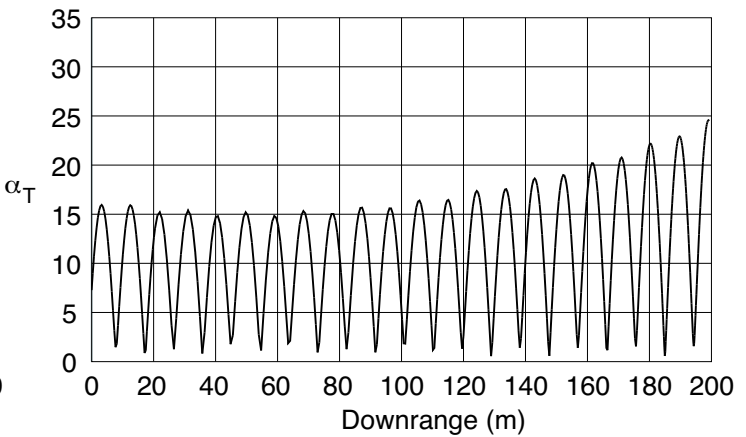

(b) Shot 32

Figure 10. Angular motion plots for large initial $\alpha_{T}$ shots.

\section{Mars Pathfinder Reconstruction}

The pitch damping data derived from the ballistic range testing was incorporated into a reconstruction simulation of the Mars Pathfinder entry. The methods of this reconstruction have been well documented by Spencer et al. ${ }^{15}$ and Gnoffo et al. ${ }^{16}$ Part of that reconstruction effort was the simulation of the capsule attitude growth using the Program to Optimize Simulated Trajectories (POST) II. ${ }^{17}$ A similar POST simulation is presented here using the new ballistic range data. The only significant difference between the MPF reconstruction simulation and the results presented here is the replacement of the Viking forced oscillation data with the $x_{c g} / D=0.27$ pitch damping values from this test series. Figure 11 shows comparison of the MER ballistic range data with Viking forced oscillation data. ${ }^{1}$ This figure shows that the ballistic range data specific to the MPF/MER shape is more dynamically unstable than the Viking data. Several qualifiers must be noted for this comparison. The Viking data was measured at $x_{c g} / D=0.21$ and should therefore be somewhat more dynamically stable than the MER data. Based on the cg sensitivity study performed in this test program, it is unlikely that the center-of-gravity position accounts for all of the differences. As no proper comparison of test methods has been done, part of the differences observed in Figure 11 may be due to test method rather than vehicle outer mold line. 


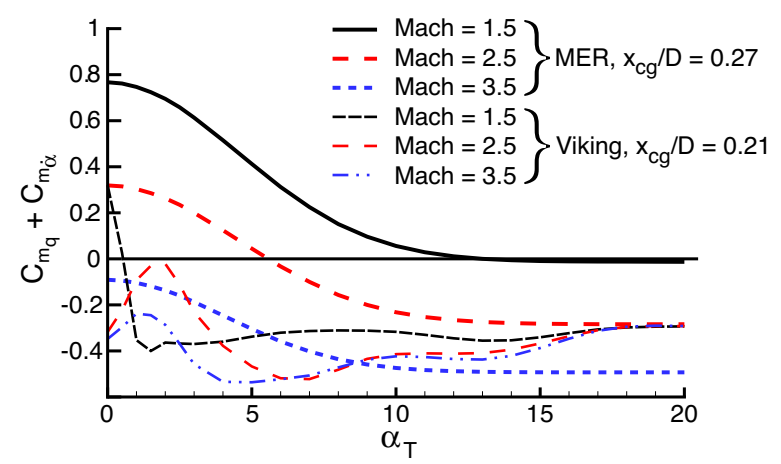

Figure 11. Comparison of Viking forced oscillation data with MER ballistic range data.

Figure 12 shows the reconstructed total angle-of-attack versus time for the POST reconstructed trajectory along with the total angle-of-attack as determined by MPF flight data. The simulation shows very good agreement with the final attitude of the vehicle at parachute deploy, better than previous efforts. ${ }^{15,16}$ The character of the growth is also well captured. The onset of the dynamic instability and the manner in which the total angle-of-attack increases with time in the last 30 seconds has been successfully recreated. The agreement between the flight data and reconstructed simulation suggests that the ballistic range data accurately describes the pitch damping of the MPF capsule and therefore MER. This close agreement further suggests that the $C_{m_{q}}$ uncertainties used in the MER database are sufficiently conservative. Using the high and low uncertainty bounds on the pitch damping coefficient fails to reproduce the MPF trajectory.

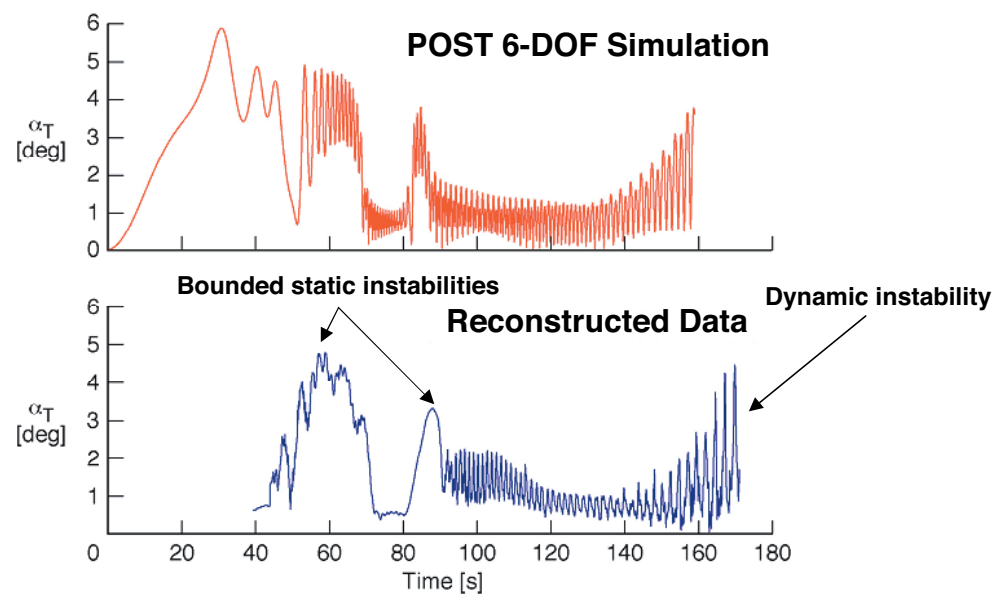

Figure 12. MPF reconstruction with ballistic range pitch damping

\section{Conclusions}

This test program has provided the most extensive set of ballistic range shots for the determination of pitch damping for a $70^{\circ}$ sphere-cone. The sensitivity of that damping to Mach number and center-of-gravity position have been determined. The pitch damping was determined from Mach $=1.5$ up to Mach $=3.5$ for a range of oscillation amplitudes from $0^{\circ}$ to well over $25^{\circ}$. The capsule is dynamically unstable at low angles-of-attack for all Mach numbers tested and the dynamic instability worsens with decreasing Mach number and aft center-of-gravity movement. The final aerodynamics recreates the ballistic range data points very well. 
The data presented here very accurately recreates the observed flight behavior of the Mars Pathfinder entry. However, additional research is needed to identify the dominant cause or causes for the differences in dynamic stability observed between Mars Exploration Rover ballistic range and Viking forced oscillation data. Models of these two configuration were tested with different backshell geometries, different center-of-gravity locations and were tested with different techniques.

\section{References}

${ }^{1}$ Steinberg, S., "Experimental Pitch Damping Derivatives for Candidate Viking Entry Configurations at Mach Numbers from 0.6 Through 3.0," TR- 3709005, Martin Marietta Corporation, 1970.

${ }^{2}$ Cheatwood, F., Winchenbach, G., Hathaway, W., and Chapman, G., "Dynamic Stability Testing of the Genesis Sample Return Capsule," AIAA 2000-1009, January 2000.

${ }^{3}$ Winchenbach, G., Chapman, G., Hathaway, W., Ramsey, A., and Berner, C., "Dynamic Stability of Blunt Atmospheric Entry Configurations," Journal of Spacecraft and Rockets, Vol. 39, No. 1, 2002, pp. 49-55.

${ }^{4}$ Teramoto, S., Hiraki, K., and Fugii, K., "Numerical Analysis of Dynamic Stability of a Reentry Capsule at Transonic Speeds," AIAA Journal, Vol. 39, No. 4, April 2001, pp. 646-653.

${ }^{5}$ Steinberg, S., Uselton, B., and Siemers, P., "Viking Configuration Pitch Damping Derivatives as Influenced by Support Interference and Test Technique at Transonic and Supersonic Speeds," AIAA 72-1012, September 1972.

${ }^{6}$ Winchenbach, G. L., "Aerodynamic Testing in a Free-Flight Spark Range," Tech. Rep. WL-TR-1997-7006, Wright Laboratory, Armament Directorate, Weapon Flight Mechanics Division (WL/MNAV), Eglin AFB, FL, April 1997.

${ }^{7}$ Yates, L. A., "A Comprehensive Aerodynamic Data Reduction System for Aeroballistic Ranges," WL-TR -96-7059, Wright Laboratory, Eglin AFB, FL, October 1996.

${ }^{8}$ Fischer, M. A. and Hathaway, W. H., "ARFDAS Users Manual," AFATL-TR -88-48, Air Force Armament Laboratory, Eglin AFB, FL, November 1988.

${ }^{9}$ Murphy, C. H., "Data Reduction for the Free Flight Spark Ranges," BRL Report 900, Aberdeen Proving Ground, MD, February 1954.

${ }^{10}$ Murphy, C. H., "Free Flight Motion of Symmetric Missiles," BRL Report 1216, Aberdeen Proving Ground, MD, July 1963.

${ }^{11}$ Hathaway, W. H. and Whyte, R. H., "Aeroballistic Research Facility Free Flight Data Analysis Using Maximum Likelihood Method," AFATL-TR -79-98, Air Force Armament Laboratory, Eglin AFB, FL, December 1979.

${ }^{12}$ Chapman, G. T. and Yates, L. A., "Limit Cycle Analysis of Blunt Entry Vehicles," AIAA 99-1022, January 1999.

${ }^{13}$ Schoenenberger, M., Cheatwood, F. M., and Desai, P. N., "Mars Exploration Rover Aerodynamic Database, Revision A," Internal MER Document, NASA LaRC, October 292003.

${ }^{14}$ Flaherty, T. M., "Aerodynamics Data Book," TR- 3709014, Martin Marietta Corporation, 1972.

${ }^{15}$ Spencer, D. A., Blanchard, R. C., Braun, R. D., Kallemeyn, P. H., and Thurman, S. W., "Mars Pathfinder Entry, Descent, and Landing Reconstruction," Journal of Spacecraft and Rockets, Vol. 36, No. 3, May-June 1999, pp. 357-366.

${ }^{16}$ Gnoffo, P. A., Braun, R. D., Weilmuenster, J. K., Mitcheltree, R. A., Engelund, W. C., and Powell, R. W., "Prediction and Validation of Mars Pathfinder Hypersonic Aerodynamic Database," Journal of Spacecraft and Rockets, Vol. 36, No. 3, May-June 1999, pp. 367-373.

${ }^{17}$ Brauer, G. L., Cornick, D. E., and Stevenson, R., "Capabilities and Applications of the Program to Optimize Simulated Trajectories (POST)," NASA CR 2770, February 1977. 